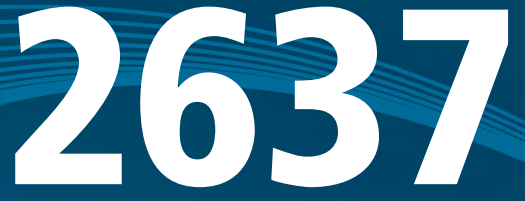

\title{
UNIVERSIDADES FEDERAIS NA PANDEMIA DA COVID-19: A FALTA DE ACESSO À INTERNET INTERDITA MESMO O ENSINO?
}

\author{
Remi Castioni \\ Adriana Almeida Sales de Melo \\ Paulo Meyer Nascimento \\ Daniela Lima Ramos
}

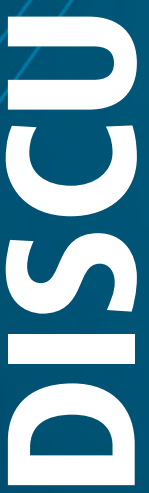

$\frac{-1}{2}$

$\frac{0}{11}$

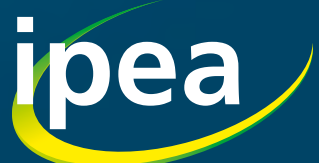





\title{
UNIVERSIDADES FEDERAIS NA PANDEMIIA DA COVID-19: A FALTA DE ACESSO À INTERNET INTERDITA MESIMO O ENSINO?'1
}

\author{
Remi Castioni ${ }^{2}$ \\ Adriana Almeida Sales de Melo 3 \\ Paulo Meyer Nascimento ${ }^{4}$ \\ Daniela Lima Ramos ${ }^{5}$
}

1. Os autores Remi Castioni, Adriana Almeida Sales de Melo e Paulo Meyer Nascimento dedicam a publicação deste texto para discussão a Daniela Lima Ramos, também coautora do trabalho. Daniela veio a falecer em 27 de setembro de 2020, pouco mais de um mês depois de a primeira versão deste texto ficar pronta e poucos dias após recebermos dois pareceres solicitando pequenos ajustes. Daniela concluiu seu doutorado em economia pela Universidade Federal da Bahia (UFBA) em 2019, com período sanduíche na University of Illinois at Urbana-Champaign. Referência por onde passava, era professora e no passado coordenou projetos de pesquisa na Superintendência de Estudos Econômicos e Sociais da Bahia (SEI). Integrava - Grupo de Pesquisa em Economia Espacial da UFBA. Suas pesquisas recentes concentravam-se em temas de econometria espacial, economia urbana, economia regional e redes econômicas. Este era seu primeiro trabalho de pesquisa diretamente relacionado a políticas educacionais. Por fim, versão deste texto foi aprovada para publicação na revista Ensaio: avaliação e políticas públicas em educação. Os autores agradecem às contribuições de dois pareceristas do Ipea, de dois pareceristas designados pela revista Ensaio e dos participantes de seminários on-line realizados pelo Programa de Pós-Graduação em Economia da UFBA (PPGE/UFBA), em 17 de julho de 2020, pelo Ipea, em 30 de julho de 2020, e pelo Centro de Gestão e Estudos Estratégicos (CGEE), em 18 de setembro de 2020. Erros e omissões remanescentes são de exclusiva responsabilidade dos autores.

2. Docente no Departamento de Planejamento e Administração da Faculdade de Educação da Universidade de Brasília (PAD/ FE/UnB).E-mail:<remi@unb.br>

3. Docente no PAD/FE/UnB. E-mail: <adrianafe@unb.br>

4. Técnico de planejamento e pesquisa na Diretoria de Estudos e Políticas Sociais (Disoc) do Ipea. E-mail: <paulo.nascimento@ipea.gov.br>

5. Doutora em economia pelo PPGE/UFBA. In memorian. 


\section{Governo Federal \\ Ministério da Economia \\ Ministro Paulo Guedes}

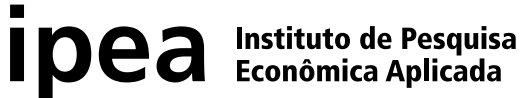

Fundação pública vinculada ao Ministério da Economia, o Ipea fornece suporte técnico e institucional às ações governamentais - possibilitando a formulação de inúmeras políticas públicas e programas de desenvolvimento brasileiros - e disponibiliza, para a sociedade, pesquisas e estudos realizados por seus técnicos.

\section{Presidente}

Carlos von Doellinger

Diretor de Desenvolvimento Institucional Manoel Rodrigues Junior

Diretora de Estudos e Políticas do Estado, das Instituições e da Democracia

Flávia de Holanda Schmidt

\section{Diretor de Estudos e Políticas \\ Macroeconômicas \\ José Ronaldo de Castro Souza Júnior}

Diretor de Estudos e Políticas Regionais, Urbanas e Ambientais

Nilo Luiz Saccaro Júnior

Diretor de Estudos e Políticas Setoriais de Inovação e Infraestrutura

André Tortato Rauen

\section{Diretora de Estudos e Políticas Sociais}

Lenita Maria Turchi

Diretor de Estudos e Relações Econômicas

e Políticas Internacionais

Ivan Tiago Machado Oliveira

\footnotetext{
Assessor-chefe de Imprensa

e Comunicação (substituto)

João Cláudio Garcia Rodrigues Lima

Ouvidoria: http://www.ipea.gov.br/ouvidoria

URL: http://www.ipea.gov.br
}

\section{Texto para Discussão}

Publicação seriada que divulga resultados de estudos e pesquisas em desenvolvimento pelo Ipea com o objetivo de fomentar o debate e oferecer subsídios à formulação e avaliação de políticas públicas.

(C) Instituto de Pesquisa Econômica Aplicada - ipea 2021

Texto para discussão / Instituto de Pesquisa Econômica Aplicada.- Brasília : Rio de Janeiro : Ipea , 1990-

ISSN 1415-4765

1.Brasil. 2.Aspectos Econômicos. 3.Aspectos Sociais. I. Instituto de Pesquisa Econômica Aplicada.

CDD 330.908

As publicações do Ipea estão disponíveis para download gratuito nos formatos PDF (todas) e EPUB (livros e periódicos).

Acesse: http://www.ipea.gov.br/portal/publicacoes

As opiniões emitidas nesta publicação são de exclusiva e inteira responsabilidade dos autores, não exprimindo, necessariamente, o ponto de vista do Instituto de Pesquisa Econômica Aplicada ou do Ministério da Economia.

É permitida a reprodução deste texto e dos dados nele contidos, desde que citada a fonte. Reproduções para fins comerciais são proibidas. 


\section{SUMÁRIO}

SINOPSE

ABSTRACT

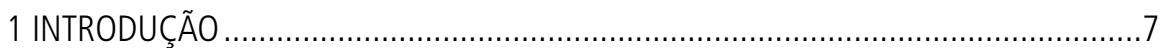

2 ESTRATÉGIAS POLÍTICO-EDUCACIONAIS DE ENFRENTAMENTO À

PANDEMIA DA COVID-19

3 COMO AS UNIVERSIDADES BRASILEIRAS REAGIRAM À PANDEMIA DA COVID-19....13

4 O ACESSO À INTERNET ENTRE ESTUDANTES DA EDUCAÇÃO SUPERIOR:

ESTIMATIVAS A PARTIR DE DADOS DO IBGE

5 CONSIDERAÇÕES FINAIS

REFERÊNCIAS 



\section{SINOPSE}

Discute-se neste texto a paralisação das atividades de ensino nas universidades federais brasileiras quando da eclosão da pandemia da Covid-19 e em que medida a falta de acesso à internet interditaria a retomada dessas atividades de forma remota. Abordam-se estratégias político-educacionais de enfrentamento à pandemia confluentes às recomendaçóes da Organização Mundial da saúde (OMS). Analisam-se as respostas imediatas das universidades quando as atividades presenciais precisaram ser suspensas. Apresentam-se dados da Pesquisa Nacional por Amostra de Domicílios Contínua (PNAD Contínua), do Instituto Brasileiro de Geografia e Estatística (IBGE), que dimensionam o tamanho do problema de acesso à internet entre estudantes da educação superior. Dado que $98 \%$ estão conectados, urge viabilizar internet e letramento digital aos $2 \%$ sem acesso. Não transparecem, todavia, justificativas consistentes para prolongar a interrupção das atividades de ensino-aprendizagem nas universidades federais. $\mathrm{O}$ ensino remoto emergencial (ERE) surge como caminho imediato em meio à pandemia, mas são as metodologias de ensino híbrido que tendem a se consolidar no mundo pós-pandemia - o que, cedo ou tarde, exigirá das universidades federais brasileiras novas atitudes e estratégias. Universalizar o acesso à internet entre seus estudantes não basta, mas é condição necessária e primordial para viabilizar o ERE e o ensino híbrido nas universidades. Ao lado das consideraçóes sobre a retomada de aulas durante e sobre o futuro das universidades federais após a pandemia da Covid-19, a grande contribuição deste texto é apresentar estimativas do tamanho do problema de falta de acesso entre estudantes de cursos superiores - problema esse, como as estimativas indicam, de tamanho insuficiente para justificar completa e prolongada interrupção das atividades de ensino-aprendizagem.

Palavras-chave: educação superior; acesso à internet; ensino híbrido; Covid-19.

\section{ABSTRACT}

This paper discusses the interruption of teaching and learning activities at Brazilian federal universities at the time the Covid-19 pandemic broke out, as well as the extent to which the lack of access to the internet would prohibit remote resumption of those activities. Political-educational strategies in line with WHO recommendations are addressed. Then the universities' immediate responses to the necessary suspension of face-to-face activities are debated. Finally, official data are used to estimate the numbers of higher education students without internet access at home. Given that $98 \%$ are connected to the internet, it is rather a matter of ensuring internet access and e-skills to those few who are not - there seem to be no consistent justifications for persisting 
with the interruption. Emergency remote teaching (ERT) boosts amid the pandemic but it is blended learning methodologies that tend to perpetuate in the aftermath of Covid-19 - sooner or later requiring new attitudes and strategies from the Brazilian federal universities. Universalizing internet access among its students does not suffice, but it is a necessary and first-order condition to make ERT and blended learning possible at the universities. Along with the considerations about the resumption of classes during the pandemic and about the future of federal universities beyond the Covid-19 pandemic, the main contribution of this text is to present estimates of the size of the problem of lack of internet access at home among university students. As the estimates suggest, that is too small a problem to justify the complete and prolonged interruption of teaching and learning activities.

Keywords: higher education; access to the internet; blended learning; Covid-19. 


\section{INTRODUÇÃO}

Em março de 2020, com a declaração da Organização Mundial de Saúde (OMS) do estado de pandemia da Covid-19, os estados brasileiros iniciaram, gradativamente, a interdição das atividades de circulação de pessoas e a indicação de isolamento social. As atividades educacionais de distintos níveis e modalidades foram suspensas em meados do mês, assim que os estados começaram a publicar seus decretos locais. Passadas algumas semanas, as instituiçóes privadas, tanto da educaçáo básica como da educação superior, a partir das orientações do Conselho Nacional de Educação (CNE) e dos conselhos estaduais de educação (CEEs), colocaram em ação plataformas de aprendizagem semelhantes às que já utilizavam na educação a distância $(\mathrm{EaD})$. O mesmo ocorreu com as secretarias de educação estaduais e municipais em distintos graus de adesão, e em relativa diferença em relação ao setor privado.

Entre as universidades públicas, as universidades estaduais paulistas náo paralisaram as atividades. Segundo o Portal de Acompanhamento da Covid-19, do Ministério de Educação (MEC), em 15 de julho de 2020, das 69 universidades federais, 53 haviam interrompido as aulas de graduação, dez estavam realizando atividades remotas e fazendo uso de tecnologias de informação e comunicação (TICs) e outras seis realizavam atividades parciais (Brasil, 2020). Com relação às aulas na pós-graduação, 29 de universidades federais estavam com atividades suspensas, $23 \mathrm{com}$ atividades mediadas por TICs, dezesseis com atividades parciais e uma relatava atividades normais.

Considerando que o ano letivo já havia sido iniciado na maioria delas, o argumento principal de tais universidades para a suspensão das atividades de ensino foi o de que nem todos os estudantes teriam acesso à internet, nem equipamentos ou letramento digital necessários que possibilitassem a realizaçáo de atividades remotas (Andifes, 2020). Diferentemente do que se passou nos Estados Unidos e na Europa, onde muitas universidades migraram do ensino presencial para o ensino remoto em poucas semanas, as universidades federais brasileiras alegaram que a limitaçáo do acesso à tecnologia e a falta de formaçáo docente e discente não permitiria transpor as disciplinas do ensino presencial para o ensino remoto. Com exceção de universidades mais concentradas em determinadas áreas do conhecimento - como as mineiras, Lavras, Alfenas e Itajubá e outras sete (Brasil, 2020) -, as demais praticamente suspenderam as atividades de ensino, negociando a retomada na modalidade remota a partir de agosto de 2020; ou seja, por volta de 150 dias após a suspensão e, mesmo assim, algumas delas com atividades suplementares ao calendário acadêmico originalmente planejado. 
Diante da pandemia, as universidades públicas se viram na presença de dois dilemas. Em primeiro lugar, a rejeição histórica da modalidade a distância, sua baixa utilização entre elas e sua associação negativa à oferta massiva do setor privado, cuja modalidade superou, em 2019, pela primeira vez na história, a matrícula presencial dos ingressantes (Inep, 2020). Em segundo lugar, um conhecimento precário sobre as condiçôes sociais de seus alunos, associado à dificuldade de fazer com eles contato individual. Tal situação pautou a realização de esforços durante vários meses, desde a realização de pesquisas tipo survey sobre o uso de computadores e os desafios reais sobre acesso à internet entre estudantes e docentes até o lançamento de editais e outras convocatórias para a compra de pacotes de dados e equipamentos e para cadastro de estudantes interessados na doação.

No caso da educação superior, seria realmente o acesso à tecnologia uma justificativa preponderante para a interrupção das atividades acadêmicas, sendo que desde 2019 a maior parte dos ingressantes já utilizava a modalidade a distância? Uma das possíveis explicaçôes pode estar na baixa atenção dada a esta modalidade pelas universidades federais, mesmo tendo sido contempladas com a criaçáo da Universidade Aberta do Brasil (UAB), por meio do Decreto no $5.800 / 2006$. A despeito da implantação nacional da UAB, e mesmo do reconhecimento legal da modalidade de ensino a distância e da criação de vasto arcabouço jurídico sobre o tema, a matrícula dessa modalidade tem majoritariamente apresentado viés de queda na década de 2010 entre as instituiçóes federais de educação superior (Ifes). No período desde a conclusão de importante expansão da educação superior federal, por meio do Programa de Apoio a Planos de Reestruturação e Expansão das Universidades Federais (Reuni), findo em 2013, as matrículas tiveram comportamento errático nesse segmento. Apesar do pico observado em 2017, quando as matriculas na EaD chegaram a 101.395 (Inep, 2018), revertendo, com um crescimento de quase $40 \%$ naquele ano em relação ao anterior, uma tendência de queda que vinha sendo observada, depois disso, as matrículas caíram 8\% em 2018 (Inep, 2019) e outros 12\% em 2019 (Inep, 2020), ano em que houve 81.119 matrículas na EaD nas federais. Já no setor privado as matrículas na $\mathrm{EaD}$ cresceram sistematicamente ao longo da década, chegando a 2019 com um número três vezes maior do que o registrado em 2010.

Perdida a oportunidade que a UAB poderia ter significado para consolidar o ensino remoto nas Ifes, o Ministério da Educação (MEC) e as próprias Ifes viram-se compelidas a discutir o ensino remoto emergencial (ERE) e a avaliação remota emergencial caminhos imediatos apontados pela literatura, ainda que não livres de dificuldades como a alternativa mais viável para não prolongar a interrupção das atividades de ensino-aprendizagem durante a pandemia. Nesse contexto, este texto discute a tendência da incorporação de metodologias de ensino híbrido na educação superior - tendência 
acelerada pela pandemia e que, cedo ou tarde, deverá exigir das universidades federais brasileiras novas atitudes e estratégias -, mas foca na questão mais básica e inicial: a garantia de conexão. Delimita, pois, a questão apenas ao acesso à internet. Não é pouco, mas há que se cuidar para não passar a impressão de que conexão garante ensino remoto. Seguramente é condição necessária e fundamental, mas é táo somente uma condição de primeira ordem.

Os desafios da transição do ensino presencial para o remoto ou para o híbrido perpassam ainda diversas outras questôes, apenas tangenciadas neste texto, por exemplo, as condiçóes de estudo remoto no domicílio (adequação do espaço, conciliação com tarefas familiares e de cuidado, entre outras). No que concerne às instituiçốes de ensino, letramento digital de discentes, docentes e técnicos administrativos e as questôes didático-metodológicas envolvidas nas profundas mudanças desencadeadas pela pandemia da Covid-19 também assumem peso central na configuração das respostas aos desafios institucionais trazidos pela nova realidade.

Feitas essas ressalvas, o objetivo deste texto é o de questionar, a partir de um olhar sobre as universidades federais brasileiras, que concentram $95 \%$ da produção da pesquisa no país (Cross, Thomson e Sinclair, 2018) e quase 1,5 milhão de alunos, se o acesso à internet pode ser considerado como um limitador para a continuidade da oferta de educação na modalidade remota, nos moldes em que foi emergencialmente implantada por ocasiáo da pandemia da Covid-19. A questão colocada aqui é que o problema de acesso demanda conhecer melhor os sujeitos que fazem parte da comunidade acadêmica e suas condiçóes de acompanhar atividades remotas. Saber quantos docentes e discentes necessitam de apoio institucional para ter acesso à internet, construir os ambientes virtuais e suas possibilidades de aprendizagem, possibilitar a utilização de equipamentos para sua inclusão imediata. Enfim, a urgência em implementar adequadamente uma conversão do ensino presencial para o remoto ou o híbrido implica desafios inesperados para docentes, para discentes e para as próprias universidades, e obrigam estas a conhecerem melhor suas capacidades e necessidades para cumprir melhor suas missóes.

Este texto está dividido em três seçôes, além desta introdução e das considerações finais. A seção 2 traça um panorama das principais estratégias adotadas na educação a partir das recomendaçôes da OMS, quanto às políticas de isolamento social, assim como aborda de que forma a educação, que já vinha apresentando processos de ampliação no uso da modalidade de educação a distância, acelerou a oferta de educação remota por meio de e-learning e outras metodologias. A seção 3 apresenta um panorama das respostas das universidades federais, as quais assumiram como dificuldade para a continuidade do 
calendário o perfil socioeconômico dos estudantes e a sua dificuldade de acesso à internet e a equipamentos necessários para a sua utilização. A seção 4 faz uso de uma fonte de dados primária, a Pesquisa Nacional por Amostra de Domicílios Contínua (PNAD Contínua), para analisar o grau de acesso domiciliar à internet entre quem cursa uma graduação e em que medida esse componente (ou a falta dele) inviabilizaria a participação em atividades remotas de ensino-aprendizagem - pelas informações apuradas, não existem justificativas consistentes para a interrupção das atividades nos moldes do que foi verificado. Por fim, as consideraçôes finais oferecem algumas alternativas para a formulação de políticas públicas, a partir da estimativa de como poderia ocorrer uma política de suporte aos que necessariamente estâo interditados do acesso à internet, visando a continuidade das atividades de ensino. Tais consideraçôes apontam para questóes de futuro na medida em que a pandemia demarcará uma nova fase na oferta educativa da educação superior em todo o mundo, a principal delas será o uso persistente do blended learning ou ensino híbrido.

\section{ESTRATÉGIAS POLÍTICO-EDUCACIONAIS DE ENFRENTAMENTO À PANDEMIA DA COVID-19}

A OMS mantém atualizada uma linha do tempo com as suas atividades relativas ao acompanhamento da pandemia da Covid-19, que sumariza sua atuação desde o período do seu surgimento como doença endêmica. Apresenta também um panorama de como a instituição foi criando protocolos de comunicação, de orientação, de prevenção e tantas outras açóes, que foram sendo seguidos e adaptados por cada país. Vários grupos foram criados na OMS, entre eles o Strategic and Technical Advisory Group on Infectious Hazards (STAG-IH), em janeiro de 2020, o qual se mostrou central na elaboração de orientaçóes, protocolos e padrôes de conduta para todo o mundo.

Também é de janeiro de 2020 a publicaçáo de documentos-guias relativos ao gerenciamento da nova doença, como: controle e prevenção da infecção, testes laboratoriais, ferramenta de revisão da capacidade nacional, comunicação de risco e engajamento social, orientação para viagens, gerenciamento clínico da doença, definições sobre vigilância de casos, até lista de produtos a serem adquiridos para prevenção, testagem e cuidado (OMS, 2020). Ainda em janeiro de 2020, havia uma preocupaçáo da OMS em tornar o setor da educação seguro para a comunidade escolar no enfrentamento da doença.

Em 11 de março de 2020, a OMS reconheceu que a Covid-19 havia alcançado a condição de pandemia, modificando seus protocolos de orientação. Sua preocupação 
com a saúde e as condiçóes de prevenção, propagação, cuidado e cura esteve sempre vinculada às condiçóes sociais nacionais, e seu discurso se intensificou no sentido de que os governos locais assumissem a condução das políticas públicas necessárias para minimizar os efeitos da pandemia. O isolamento social, a testagem em massa e o aumento de leitos - incluindo o aumento no número de profissionais, instalaçóes e equipamentos - tornaram-se preocupação central da OMS, além da investigação sobre origem, tratamento e vacina, com o aconselhamento também da suspensão de muitas atividades, abrangendo também a educação.

Atingindo países em níveis diferentes de desenvolvimento da pandemia, tais recomendaçôes foram seguidas de diferentes formas. No Brasil, esta variação de respostas quanto às políticas educacionais reflete as características de nossa República Federativa, que estabelece o regime de colaboração com os entes subnacionais. Gradativamente, as instituiçôes públicas e privadas da educação básica e superior também foram assumindo protocolos diversos de suspensáo de atividades, em prol do isolamento social, respondendo também às decisōes político-administrativas locais.

Diversos protocolos foram criados nos países, em relação à condução das políticas educacionais. A esse respeito, vale destacar um dos estudos elaborados sobre o tema pela Organização para a Cooperaçáo e Desenvolvimento Econômico (OCDE), de autoria de Reimers e Schleicher (2020), que propóe grupos de categorias para a construçáo de padróes e índices para se entender mundialmente as respostas nacionais relativas principalmente à educação, assim como construir caminhos para o monitoramento e investigaçóes futuras.

Seguindo as recomendaçôes do estudo e analisando sua adequação aos problemas enfrentados pela educação superior, como sugestão para um primeiro grupo de categorias, a pesquisa aponta que os países investigados procederam ao reconhecimento da Covid-19 como pandemia a partir das recomendaçôes da OMS. Seria necessário relacionar as respostas imediatas das políticas educacionais em relação às políticas de saúde, investigar as parcerias locais, assim como as mudanças político-administrativas realizadas para lastrear as mudanças necessárias quanto ao período inicial de suspensão de aulas e outras atividades.

Outro grupo de categorias a serem criadas seria relativo à definição local de novos conceitos jurídicos e administrativos para respaldar as açóes políticas, principalmente em relação à regulamentação do trabalho remoto e das condiçôes para a realização do ERE. 
Um terceiro grupo de categorias seria construído com as respostas relativas às mudanças nas questóes didático-pedagógicas, de currículo, de formação de professores e, principalmente, de construção de ferramentas para a educaçáo remota adequadas ao período de isolamento social e paulatina volta às atividades presenciais. Aqui também seriam categorizadas as respostas locais sobre as formas de prover acesso, equipamentos, assessoria e formação para a $\mathrm{EaD}$ a docentes, funcionários e discentes.

No quarto grupo seriam categorizadas as diversas formas que os países utilizaram para a criação de redes de comunicação oficial, assim como de escuta das experiências locais e, finalmente, em um quinto grupo seriam relacionados os tipos de acompanhamento, monitoramento e avaliação permanente dos processos criados (Reimers e Schleicher, 2020).

Considerando o objetivo deste estudo, priorizamos os conceitos presentes no terceiro grupo descrito como bases para a discussão sobre as respostas das universidades brasileiras relativas aos primeiros meses de enfrentamento da pandemia da Covid-19.

A educação remota, realizada de diversas formas em conjunto com a utilização intensa das tecnologias que permitem a EaD (Rovai e Jordan, 2004), tem se tornado uma opçáo adequada para o momento histórico de isolamento social como política pública de saúde adotada por diversos países do mundo.

As formas de produção e gestão de conhecimento realizadas pela educação superior sofreram grandes rupturas desde o final do século passado e as questóes relativas às novas formas de aprendizagem mais centradas no sujeito que aprende, assim como as metodologias ativas de ensino, voltam com novas roupagens para ajudar a pensar as necessidades contemporâneas da educação superior (Teodoro e Vasconcelos, 2005). No século XXI, as questóes que envolvem a blended learning, ou educação mista ou híbrida, estão relacionadas ao conceito de lifelong learning, ou aprendizagem ao longo da vida, e buscam superar, na educação superior, o lecture-based paradigm, paradigma baseado em conferências e as aulas expositivas.

Os desafios que advêm do enfrentamento da pandemia da Covid-19 obrigaram as instituições educacionais a repensarem suas atividades e a sua relaçáo com as diversas TICs, a formação para uma nova cidadania digital e as suas próprias estratégias de governança.

As universidades também se viram obrigadas a repensar suas atividades: suspendendo açôes em uma primeira fase, revendo sua relação com as suas múltiplas atividades e a educaçáo presencial em um segundo momento; viram a demanda pelo uso e suporte 
da educação não presencial aumentar de forma para a qual não estavam preparadas (Hodges et al., 2020). As instituiçóes que responderam mais rapidamente e que conseguiram instituir de forma massiva práticas teórico-metodológicas de e-learning, de ensino remoto - nos níveis de graduação e pós-graduação - foram as que já haviam instituído tais práticas, mesmo que em faculdades ou cursos específicos.

Para alguns autores, os conceitos de ERE e de avaliação remota emergencial são mais adequados para descrever as práticas decorrentes da primeira fase de enfrentamento da pandemia, pois não se tratou de imediato de rever a $\mathrm{EaD}$ nas instituiçôes, mas de construir respostas emergenciais para a suspensão presencial de diversas atividades. Universidades que já haviam construído açóes como uso de banco de aulas virtuais, ou que já haviam incorporado o uso de dispositivos móveis às atividades de ensino, puderam repensar novos desenhos instrucionais e novas possibilidades de construção de conhecimento mais rapidamente (Hodges et al., 2020). No entanto, as dificuldades advindas de tais mudanças também promoveram o acirramento ou fizeram aflorar problemas já latentes, exigindo a criação de novos protocolos para as questóes de acesso e permanência, como o abandono ou evasão dos cursos (Donoso-Díaz, Iturrieta e Traverso, 2018).

A paulatina volta às atividades presenciais também se tornou uma preocupação e objeto de investigação, pois as experiências de ações virtuais voltadas ao ensino estão trazendo bons resultados em muitos casos e não deverão ser esquecidas, pelo que uma das propostas em foco em todo o mundo é o do ensino híbrido, que está mesclando, a partir de diferentes propostas, as experiências aprendidas com a primeira fase de enfrentamento da pandemia da Covid-19, às modificaçôes no ensino presencial.

\section{COMO AS UNIVERSIDADES BRASILEIRAS REAGIRAM À PANDEMIA DA COVID-19}

No Brasil, a EaD apresenta uma história que remonta ao começo do século XX, com o registro de cursos profissionalizantes por correspondência, os quais foram evoluindo em concomitância com a criação de novos meios de comunicação. $\mathrm{O}$ ensino por rádio e por televisão inovaram a $\mathrm{EaD}$, mas foram o crescimento e a popularização da internet que deram escala a atividades remotas de ensino-aprendizagem e ampliaram as possibilidades envolvendo essa modalidade.

Amplamente investigada em todo o mundo, as questóes relativas à EaD envolvem a relação da formação docente com as questôes didático-pedagógicas de sua utilização. 
Valente e Almeida (2020) fizeram uma reconstituição das iniciativas no âmbito do MEC sobre o uso das tecnologias na educação no Brasil e demonstraram a abrangência que tais iniciativas tiveram, tanto no sistema federal como nos entes subnacionais, envolvendo desde metodologias à distribuição de equipamentos, a exemplo da última iniciativa com o Projeto Um Computador por Aluno (UCA). Ainda que as experiências oriundas de trinta anos de açóes contínuas não tenham sido tão animadoras, demonstraram os autores que, no momento da eclosão da pandemia da Covid-19, o Brasil sustentava trajetória consistente de uso de tecnologias na educação, embora fossem críticos da sua orientaçáo top-down, negligenciando o papel dos professores em sala de aula. A pandemia mudou drasticamente esta realidade, reduzindo a dependência das orientaçóes do MEC e dando maior protagonismo aos professores, que se viram compelidos a decidir por variadas abordagens, levando em consideração não só o uso de determinada tecnologia, mas a sua recepção por parte dos alunos. A pandemia deu sentido, em alguns contextos, a tecnologias que já estavam superadas no âmbito das atividades de ensino-aprendizagem, como televisão, rádio e até material por correspondência.

Em 17 de março de 2020, por meio da Portaria no 343, o MEC autorizou por trinta dias a substituiçấo das aulas presenciais por aulas que utilizassem meios e tecnologias de informação e comunicação. A esta portaria se sucederam outras duas: a de $\mathrm{n}^{\mathrm{0}} 345$, de 19 de março de 2020, e a de no 473 , de 12 de maio de 2020, sempre prorrogando por mais trinta dias. Por meio da Portaria no 544, de 16 de junho de 2020, o MEC autorizou o uso das plataformas de aprendizagem até o final de 2020, excetuando-se os cursos que necessariamente demandassem atividades presenciais. $\mathrm{O} C N E$, por meio do Parecer no 5/2020, aprovado em 28 de abril de 2020 e homologado pelo MEC em 1ํ de junho, já havia flexibilizado o calendário acadêmico, desobrigando o cumprimento dos duzentos dias letivos, o que também ficou assegurado na Medida Provisória no 934, de $1^{\circ}$ - de abril de 2020, aprovada pelo Congresso Nacional e convertida na Lei no ${ }^{\circ} 14.040$, de 18 de agosto de 2020 .

Do ponto de vista legal, as universidades tiveram total respaldo para a migração das suas atividades, porém, com exceção de algumas universidades, o que se observou foi a decretação pelos conselhos superiores das distintas instituições, a partir de meados de março de 2020, da suspensão total das atividades de ensino de graduaçáo e de pós-graduação. 
Somente após noventa dias, com às atividades de ensino paralisadas, a maioria das universidades federais iniciou pesquisas para investigar a situaçáo social dos seus alunos e docentes durante a pandemia. Nesse período, a criação de diversos comitês voltados à Covid-19 nas suas várias dimensões foram instalados pelas universidades para estabelecer medidas de segurança e protocolos para um possível retorno, comitês para acolhimento de estudantes que manifestassem necessidades de assistência, comitês para o desenvolvimento de projetos de combate à pandemia e até de doação de equipamentos de proteção individual (EPIs), além da abertura de editais para convocação de interessados em receber computadores, pacote de dados para o acompanhamento das aulas que começaram a ser programadas para meados de agosto de 2020.

Um dos argumentos para a não retomada das atividades de ensino residiu na realização de pesquisas para saber a real condição social dos estudantes e dos docentes. Estas consultas tipo survey investigaram a sua familiaridade com a tecnologia, seus usos e frequência de acesso e pretendiam abarcar toda a comunidade acadêmica. Porém, o índice de respostas não foi tão expressivo, abaixo de $50 \%$ no caso dos estudantes e entre $60 \%$ a $80 \%$ entre os docentes das universidades que divulgaram seus dados, a exemplo da Universidade Federal do Rio de Janeiro (UFRJ), da Universidade Federal Fluminense (UFF), da Universidade de Brasília (UnB) e da Universidade Federal de Pernambuco (UFPE). Revelaram-se, na maioria dos casos, situaçôes que eram previsíveis.

No caso dos estudantes, o cadastro que cada universidade federal mantém dos seus beneficiários do Programa Nacional de Assistência Estudantil (PNAES) já seria um ponto de partida mais fidedigno para mapear estudantes que demandariam suporte para viabilizar acesso a atividades remotas de ensino-aprendizagem. Ademais, os recursos programados para o PNAES - R $\$ 1,038$ bilhão no Orçamento Geral da Uniáo (OGU) para $2020^{1}$ - podem ser utilizados para inclusão digital, conforme o $\$ 1^{\circ}$ do art. $3^{\circ}$ do Decreto no $7.234 / 2010$, que dispóe sobre o programa. Em julho de 2020, já passados, portanto, quatro meses da eclosão da pandemia, o MEC anunciou a contrataçáo emergencial, por meio da Rede Nacional de Ensino e Pesquisa (RNP), de pacote de dados móveis para alunos em condição de vulnerabilidade socioeconômica (RNP, 2020). Essa iniciativa envolve as Ifes, os institutos federais, os centros federais de educação tecnológica (Cefets) e o Colégio Pedro II, desonerando, consequentemente, o próprio PNAES desse encargo.

1. Dados do Siga Brasil. Disponível em: <https://bit.ly/3quM8x0>. 
Com as atividades suspensas na maioria das universidades federais, foi sendo autorizado o retorno às atividades após longas discussóes nos conselhos de ensino pesquisa e extensão (Cepes), em jornadas de debates que atravessaram longas horas e onde foi sendo consagrado o conceito de ERE, embora sua definição não constasse nas orientaçóes oficiais do MEC e nem do CNE. ${ }^{2}$

Uma das questóes presentes nos debates dos conselhos superiores das universidades foi o lema: "não deixar ninguém para trás", invocado pelos estudantes e incorporado ao discurso dos dirigentes das universidades. O lema é uma alusão a campanha da Organização das Nações Unidas (ONU), no âmbito dos Objetivos de Desenvolvimento Sustentável (ODS). Entretanto, em que pese a necessidade de dar condiçôes a todos terem acesso aos meios para continuar acompanhando as aulas, as bases que sustentam a afirmação de que os estudantes das universidades públicas têm maiores dificuldade de acesso ao ERE em relação aos estudantes das instituiçóes privadas de educação superior, que concentram a maior parte das matrículas, parece não se sustentar pelos dados que oferecemos a seguir com base na PNAD Contínua.

Antes disso, porém, registre-se que as convocatórias organizadas pelas universidades para suprir a carência do acesso a internet para o acompanhamento das aulas, os dados revelados por algumas das universidades onde o debate do "não deixar ninguém para trás" foi mais candente, demonstrou que poucos estudantes se interessaram pelo apoio. Na UFRJ, de uma estimativa inicial de 13 mil chips, apenas 3.253 estudantes compareceram para solicitar o benefício. $\mathrm{Na} \mathrm{UnB}$, apenas 739 estudantes solicitaram auxílio para acesso a internet. $\mathrm{O}$ fato é que nem entre os beneficiários da PNAES a falta de acesso a internet chega a ser um problema tão abrangente como se supunha. 


\section{ACESSO À INTERNET ENTRE ESTUDANTES DA EDUCAÇÃO SUPERIOR: ESTIMATIVAS A PARTIR DE DADOS DO IBGE}

Desde 2016, o Instituto Brasileiro de Geografia e Estatística (IBGE) aplica, no quarto trimestre de cada ano, um questionário suplementar de TIC aos domicílios visitados pela PNAD Contínua. Os microdados ${ }^{3} \mathrm{da}$ PNAD Contínua permitem filtrar as respostas de quem frequentava curso de graduação no momento da pesquisa. É possível, inclusive, analisar em separado as respostas de quem frequentava graduação em instituiçóes de educação superior (IES) públicas e privadas. ${ }^{4}$ No momento em que eclodiu a crise decorrente da pandemia da Covid-19, que levou universidades federais a suspender seus semestres letivos, os dados mais recentes divulgados desse questionário referiam-se a 2018.

O questionário suplementar de TIC da PNAD Contínua 2018 traz informaçôes sobre 554.211 pessoas, sendo que parte das perguntas foi direcionada a pessoas de 10 anos de idade ou mais - o que reduz a amostra total, para essas perguntas, a 481.386 pessoas. Destas, 19.429 declaravam frequentar um curso de graduaçáo naquele ano - amostra que interessa ao presente estudo. Aplicando os pesos amostrais disponibilizados pelo próprio IBGE aos microdados divulgados, pode-se, por exemplo, chegar à proporção de estudantes e da populaçáo em geral que, no último trimestre de 2018, acessava internet em algum local (mesmo que não fosse no domicílio) e que tinha celular próprio, bem como a proporção de domicílios (e, por extensão, de seus moradores) que dispunha de conexáo à internet, que tipo de conexão era essa e se havia algum serviço de rede móvel celular cujo sinal pudesse ser captado para telefonia ou internet dentro do domicilio. Também permitem averiguar a distribuição dessas variáveis por diversos recortes, a exemplo de gênero, cor/raça, tipo de IES, regiáo de moradia, situação do domicílio (urbano ou rural) ou faixas de renda domiciliar per capita.

Dois fatos destacam-se de imediato quando tais dados são analisados. Primeiro, a proporção com acesso à internet é maior entre estudantes de graduaçáo $(99,3 \%)$ do que na média da população com 10 ou mais anos de idade (74,7\%). Segundo, não há diferença significativa nesse quesito entre estudantes de IES públicas $(99,0 \%)$ e estudantes de IES privadas $(99,4 \%)$.

3. 0 download dos microdados utilizados neste trabalho é feito a partir do link: <https://bit.ly/2YH7Frf $>$. Devendo ser abertas, na sequência, as pastas Anual, Microdados, Trimestre, para então encontrar o arquivo .zip relacionado ao quarto trimestre na pasta Trimestre_4. Os microdados foram importados para o software Stata 16, no qual as análises foram feitas. 4. Não é possível, contudo, separar por tipo de IES pública (federal, estadual ou municipal) e por tipo de IES privada (com ou sem fins lucrativos), apenas entre os segmentos público e privado. 
Por acesso à internet deve ser entendida a proporção de indivíduos que, nos três meses anteriores à aplicaçáo do questionário, utilizou a internet em algum local (domicílio, local de trabalho, escola, centro de acesso gratuito ou pago, domicílio de outras pessoas ou qualquer outro local) por meio de microcomputador, tablet, telefone móvel celular, televisão ou outro equipamento.

Em um cenário de pandemia, para além de acesso em algum local (que pode se tornar inviável sob imposiçôes de distanciamento social), as atividades de ensino-aprendizagem devem pressupor acesso, em casa, a uma conexáo de internet em banda larga ou, ao menos, por sinal de rede móvel celular 3G ou 4G. Para fins de política pública, portanto, cabe mapear e descrever - da forma mais detalhada possível - a parcela de estudantes sem acesso domiciliar à tecnologia necessária para atividades remotas de ensino-aprendizagem, inescapáveis em tempos de pandemia e possivelmente de recorrente uso mesmo depois de controlada a Covid-19. Os dados do IBGE permitem fazer isso, sendo os dados sobre acesso domiciliar às TICs mais apropriados para fins do presente estudo do que os dados sobre acesso a partir de qualquer lugar.

A tabela 1 traz as quantidades de estudantes de graduação sem acesso domiciliar à internet estimadas a partir dos microdados do questionário suplementar de TIC da PNAD Contínua 2018. Apresentam-se as estimativas para variados recortes por quatro grupos: mulheres negras ou indígenas; mulheres brancas ou amarelas; homens negros ou indígenas; e homens brancos ou amarelos. Traz as estimativas dos totais dessas pessoas da educação superior, destacando, em seguida, quantas delas estariam, em 2018, impossibilitadas de acompanhar atividades remotas de ensino-aprendizagem por não terem acesso domiciliar à internet com qualidade mínima para acessar, sem maiores interrupções, conteúdos educacionais que incluam vídeos e chamadas. Incluíram-se nessa categoria tanto os estudantes de graduação que habitavam domicílios sem acesso algum à internet, quanto os que dispunham de acesso apenas por conexão discada por linha telefônica. 


\section{TABELA 1}

Perfil dos discentes de graduação sem acesso domiciliar à internet em banda larga ou 3G/4G, por cor/raça, tipo de instituição, localização do domicílio do estudante e renda Brasil (2018)

\begin{tabular}{|c|c|c|c|c|c|}
\hline Frequentavam uma graduação & $\begin{array}{l}\text { Mulheres negras ou } \\
\text { indígenas }\end{array}$ & $\begin{array}{c}\text { Mulheres brancas ou } \\
\text { amarelas }\end{array}$ & $\begin{array}{l}\text { Homens negros ou } \\
\text { indígenas }\end{array}$ & $\begin{array}{c}\text { Homens brancos ou } \\
\text { amarelos }\end{array}$ & Total \\
\hline \multicolumn{6}{|c|}{ Por tipo de instituição de ensino superior (IES) } \\
\hline Públicas & 543.518 & 518.762 & 507.100 & 479.801 & 2.049 .181 \\
\hline Sem acesso domiciliar à internet & $\begin{array}{l}21.776 \\
(4,0 \%)\end{array}$ & $\begin{array}{l}11.911 \\
(2,3 \%)\end{array}$ & $\begin{array}{l}20.520 \\
(4,0 \%)\end{array}$ & $\begin{array}{r}5.960 \\
(1,2 \%)\end{array}$ & $60.167(2,9 \%)$ \\
\hline Privadas & 1.623 .700 & 1.750 .394 & 1.179 .541 & 1.285 .216 & 5.838 .851 \\
\hline Sem acesso domiciliar à internet & $\begin{array}{l}41.330 \\
(2,5 \%)\end{array}$ & $\begin{array}{l}21.965 \\
(1,2 \%)\end{array}$ & $\begin{array}{l}19.025 \\
(1,6 \%)\end{array}$ & $\begin{array}{l}12.560 \\
(1,0 \%)\end{array}$ & $94.880(1,6 \%)$ \\
\hline \multicolumn{6}{|c|}{ Por região de localização do domicílio } \\
\hline Norte & 296.425 & 102.371 & 232.356 & 68.540 & 699.692 \\
\hline Sem acesso domiciliar à internet & $\begin{array}{l}13.109 \\
(4,4 \%)\end{array}$ & $\begin{array}{r}2.421 \\
(2,4 \%)\end{array}$ & $\begin{array}{r}8.675 \\
(3,7 \%)\end{array}$ & $\begin{array}{r}1.321 \\
(1,9 \%)\end{array}$ & $25.526(3,6 \%)$ \\
\hline Nordeste & 717.213 & 317.981 & 545.132 & 256.472 & 1.836 .798 \\
\hline Sem acesso domiciliar à internet & $\begin{array}{l}31.343 \\
(4,4 \%)\end{array}$ & $\begin{array}{l}10.321 \\
(3,2 \%)\end{array}$ & $\begin{array}{l}20.189 \\
(3,7 \%)\end{array}$ & $\begin{array}{r}7.018 \\
(2,7 \%)\end{array}$ & $68.871(3,7 \%)$ \\
\hline Sudeste & 777.571 & 1.102 .920 & 621.500 & 860.667 & 3.362 .658 \\
\hline Sem acesso domiciliar à internet & $\begin{array}{l}10.230 \\
(1,3 \%)\end{array}$ & $\begin{array}{l}10.602 \\
(1,0 \%)\end{array}$ & $\begin{array}{r}6.674 \\
(1,1 \%)\end{array}$ & $\begin{array}{r}3.625 \\
(0,4 \%)\end{array}$ & $31.131(0,9 \%)$ \\
\hline Sul & 134.347 & 581.693 & 107.684 & 447.750 & 1.271 .474 \\
\hline Sem acesso domiciliar à internet & $\begin{array}{r}3.558 \\
(2,7 \%)\end{array}$ & $\begin{array}{r}7.378 \\
(1,3 \%)\end{array}$ & $\begin{array}{r}761 \\
(0,7 \%)\end{array}$ & $\begin{array}{r}5.304 \\
(1,2 \%)\end{array}$ & $17.001(1,3 \%)$ \\
\hline Centro-Oeste & 241.661 & 164.191 & 179.970 & 131.589 & 717.411 \\
\hline Sem acesso domiciliar à internet & $\begin{array}{r}4.867 \\
(2,0 \%)\end{array}$ & $\begin{array}{r}3.153 \\
(1,9 \%)\end{array}$ & $\begin{array}{r}3.245 \\
(1,8 \%)\end{array}$ & $\begin{array}{r}1.252 \\
(0,9 \%)\end{array}$ & $12.517(1,7 \%)$ \\
\hline \multicolumn{6}{|c|}{ Por situação do domicílio (urbana ou rural) } \\
\hline Urbana & 2.042 .489 & 2.172 .412 & 1.610 .166 & 1.700 .711 & 7.525.778 \\
\hline Sem acesso domiciliar à internet & $\begin{array}{l}40.840 \\
(2,0 \%)\end{array}$ & $\begin{array}{l}26.031 \\
(1,2 \%)\end{array}$ & $\begin{array}{l}22.688 \\
(1,4 \%)\end{array}$ & $\begin{array}{l}14.790 \\
(0,9 \%)\end{array}$ & $104.349(1,4 \%)$ \\
\hline Rural & 124.729 & 96.744 & 76.475 & 64.307 & 362.255 \\
\hline Sem acesso domiciliar à internet & $22.267(17,8 \%)$ & $7.844(8,1 \%)$ & $16.856(22,0 \%)$ & $3.730(5,8 \%)$ & $50.697(14,0 \%)$ \\
\hline \multicolumn{6}{|c|}{ Por faixa de rendimento domiciliar per capita } \\
\hline $\begin{array}{l}\text { Baixa renda } \\
\text { (até 1,5 salário mínimo) }\end{array}$ & 1.490 .957 & 1.111 .100 & 973.760 & 702.596 & 4.278.413 \\
\hline Sem acesso domiciliar à internet & $58.081(3,9 \%)$ & $23.028(2,1 \%)$ & $35.258(3,3 \%)$ & $10.550(1,5 \%)$ & $126.917(3,0 \%)$ \\
\hline
\end{tabular}

Fonte: IBGE (2018).

Elaboração dos autores.

Obs.: As porcentagens entre parênteses referem-se à proporção sem acesso domiciliar à internet no respectivo recorte a que se refere o número que precede o parêntese. Assim, por exemplo, os 16.856 homens negros ou indígenas que, estima-se, estavam matriculados em curso superior, domiciliados em área rural e sem acesso domiciliar à internet representavam $22,0 \%$ de todos os 76.475 homens negros ou indígenas que, estima-se, estavam matriculados em curso superior e domiciliados em área rural no momento da aplicação do questionário suplementar da PNAD Contínua 2018 sobre TIC.

Para se chegar aos números reportados na tabela 1, primeiro foram tabuladas, por grupo de gênero e cor/raça, as proporções de pessoas que frequentavam graduação, respectivamente por tipo de IES (pública ou privada), região de localização do domicílio 
(Norte, Nordeste, Sudeste, Sul ou Centro-Oeste), situação do domicílio (urbano ou rural) e vulnerabilidade econômica (assumiu-se como baixa a renda domiciliar per capita de até 1,5 salário-mínimo, patamar mais usual para caracterizar baixa renda nos programas do MEC). Como a amostra da PNAD Contínua é representativa para o Brasil, é possível estimar, a partir dela, o número de estudantes para cada recorte apresentado na tabela 1.

Necessário ressaltar, contudo, que o total de indivíduos (7,9 milhóes) não coincide com o total de matrículas registradas no mesmo ano pelo Censo da Educação Superior (8,4 milhóes). ${ }^{5}$ Isto se deve a dois motivos principais. Primeiro, porque a PNAD Contínua refere-se a indivíduos e domicílios. Um mesmo indivíduo pode ter múltiplas matrículas. Segundo, porque os números levantados a partir da PNAD Contínua 2018 e reportados na tabela 1 são estimativas. Não são uma contagem efetiva de estudantes. Como estimativas que são, devem ser tomadas como aproximaçóes da realidade.

Optou-se por reportar quantidades (não apenas proporçóes) por ser intuito deste trabalho estimar número de estudantes de educação superior sem acesso à internet em casa para atividades remotas de ensino-aprendizagem. Embora o trabalho busque discutir desafios para viabilizar acesso de todo o corpo discente das universidades federais na retomada dos semestres interrompidos por conta da pandemia do novo corona-vírus, a tabela 1 é relevante por fornecer um quadro geral do acesso à internet em casa entre estudantes de graduação como um todo.

Vê-se, no quadro geral delineado pela tabela 1, que, em termos absolutos, em 2018, 155 mil estudantes de graduação (aproximadamente 95 mil em IES privadas e 60 mil em IES públicas) não tinham acesso domiciliar à internet em banda larga ou por sinal de rede móvel celular 3G ou 4G. Esse número representa aproximadamente 2\% do total de estudantes de nível superior. Dado que $98 \%$ dos estudantes estão conectados à internet, é uma questão de garantir acesso à internet e letramento digital para os $2 \%$ sem acesso - portanto, não transparecem justificativas consistentes para prolongar a interrupção das atividades de ensino-aprendizagem.

Essa dimensão reduzida não deve ser interpretada como se fosse inexistente o problema do acesso em nível superior. O problema já existia em 2018 (quando os dados usados neste texto foram coletados), e é possível que tenha se tornado maior ao longo de 2020. Isto porque os campi de instituiçóes de ensino superior localizam-se majoritariamente em espaços urbanos e é possível que parte de seus estudantes, que migram

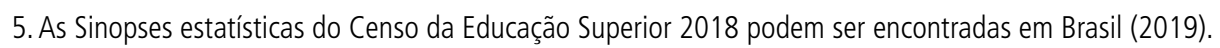


mais para estudar do que os da educação básica, tenham retornado a seus domicílios de origem durante a pandemia - hipótese que pode significar maiores proporçôes sem acesso adequado à internet em 2020 do que em 2018.

Ademais, outras questóes que não são aprofundadas neste texto (escapam a seu escopo) também dificultam a transiçáo do ensino presencial para o remoto e para o ensino híbrido, por exemplo, as condiçóes para estudo remoto no domicílio (adequação do espaço, conciliação com tarefas familiares e de cuidado, entre outras). Especificamente em relação às instituiçôes de ensino, letramento digital de discentes, docentes e técnicos administrativos e as questóes didático-metodológicas envolvidas nas transformaçóes impostas pela pandemia da Covid-19 colocam-se também como fator a condicionar as respostas das universidades a esses novos e inesperados desafios institucionais. Com efeito, este é um debate complexo e multifacetário, pois, para além das soluçóes tecnológicas disponíveis, envolve letramento digital, formação continuada e diversas adaptaçóes pedagógicas e gerenciais nada triviais - além das restriçôes econômicas, sociais e culturais a que possam estar submetidas parcelas da população estudantil afetada e do próprio corpo docente e técnico-administrativo envolvido no processo de ensino-aprendizado.

Destaque-se, igualmente, que a exclusáo digital tem cor e renda bem pronunciadas: cerca de dois terços desses estudantes eram pessoas negras ou indígenas, como também eram cerca de dois terços as que tinham renda domiciliar per capita de até 1 salário-mínimo. A regra dos dois terços aparece também quanto à situação do domicílio: é essa a proporção que residia em áreas urbanas. $\mathrm{Na}$ distribuição por regiōes geográficas, a maior parte dos estudantes de graduaçáo sem acesso de qualidade à internet morava na regiáo Nordeste (cerca de 40\%), embora estivesse na regiáo Norte a proporção maior de graduandos sem acesso domiciliar à internet em banda larga ou por sinal de rede móvel celular $3 \mathrm{G}$ ou $4 \mathrm{G}(2,0 \%$, contra $1,1 \%$ no Nordeste, $0,6 \%$ no Centro-Oeste, $0,4 \%$ no Sudeste e $0,2 \%$ no Sul).

Conquanto sejam relativamente poucos os estudantes de graduação sem acesso domiciliar à internet, a exclusão digital reflete e reforça desigualdades. Os estudantes mais afetados são aqueles que já se encontram em desvantagens de oportunidades em razão de condiçôes econômicas e sociais piores do que as de alunos com acesso ao ensino remoto. A dificuldade em estudar durante o período da pandemia pode ser uma fonte de ampliação da desigualdade no futuro. 
Schwartzman (2020) coloca como questáo central proporcionar ERE para a grande maioria que tem meios para acessá-lo, cabendo um trabalho adicional de suporte aos que não dispóem (por exemplo, distribuindo tablets com chips de dados). Nascimento et al. (2020) mostram que solução assim resolveria o problema para mais de $60 \%$ dos estudantes de graduação sem acesso domiciliar à internet. Os demais, entretanto, ainda precisariam de um local com disponibilidade de sinal de internet, pois em seus domicílios sequer chega sinal de rede móvel celular, requisito para o acesso à internet por chip de dados. Mesmo essa não seria uma dificuldade que justifique a náo retomada das atividades de ensino-aprendizagem nas Ifes: os dados do Censo da Educaçáo Superior apontam para uma quase universalização da cobertura de internet nos campi dessas instituiçôes. $\mathrm{O}$ acesso à tecnologia (em casa ou no campus, neste caso de maneira escalonada e ordenada para evitar aglomeraçôes) mostra-se, assim, a questão de mais fácil remediação. A resolução completa do problema passa, outrossim, por desafios pedagógicos e gerenciais, como também por estratégias para desenvolver nos estudantes, docentes e técnicos administrativos que necessitem - o letramento digital indispensável ao ERE.

\section{CONSIDERAÇÕES FINAIS}

Adotar o ERE está configurando as respostas institucionais assumidas pelas universidades públicas brasileiras à semelhança de várias outras instituiçôes similares em todo o mundo, em resposta aos desafios e às necessidades impostas pela pandemia da Covid-19. As questóes relativas à criação de soluçóes para o desenvolvimento do ERE dependem não apenas, mas é pré-requisito - do acesso dos sujeitos à internet em suas moradias, onde convivem com as dificuldades individuais e familiares, laborais e culturais relativas às diversas políticas de isolamento social.

Do ponto de vista da instituição, a garantia de acesso à internet e aos equipamentos necessários aos técnicos e docentes, bem como a formação docente e discente; as questóes de criação, suporte e manutenção de ambientes virtuais, a gestão do conhecimento, o monitoramento e a avaliação das açóes de ensino-aprendizagem; a criação de informaçôes novas sobre os novos processos; e o gerenciamento das questóes jurídico-administrativas que possibilitem e legitimem o uso do ERE tornam-se questôes essenciais para a sobrevivência institucional. Do ponto de vista dos sujeitos, a abertura e disponibilidade para mergulhar em novos aprendizados, novo ritmo de trabalho e cultura organizacional, assim como o reconhecimento dos próprios limites relativos ao aprendizado de tantas novas questões, envolvendo todas as dimensôes da própria vida, tornam a relação com o ERE mais difícil. 
O problema de acesso à internet entre estudantes da educação superior é relativamente reduzido e localizado. Segundo as estimativas apresentadas neste texto, a partir da análise dos dados da PNAD Contínua 2018, ele atinge apenas cerca de $2 \%$ do universo de estudantes de cursos superiores. Recorrendo aos mesmos dados, Nascimento et al. (2020) mostram que a quantidade de estudantes sem acesso à internet alcança $10 \%$ do total de estudantes no ensino médio, $16 \%$ no ensino fundamental e de $14 \%$ a $15 \%$ na pré-escola. Apesar de o problema na educação superior ser menor em quantidade, ele atinge, sobretudo, estudantes de baixa renda, minorias étnicas e domiciliados em regiôes mais pobres do país. Enfrentar esse problema assume um claro caráter de promoção da equidade, portanto. Assim, distribuir chips de dados e equipamentos para esses estudantes é fundamental, política que pode - e deve - ser complementada com a abertura dos campi em horários específicos e pré-agendados para estudantes que não conseguem acesso mesmo se lhes forem fornecidos os equipamentos necessários. Nascimento et al. (2020) mostram que nem todos os domicílios dispóem de infraestrutura para acesso à internet, pois sequer captam sinal de celular.

Conhecer melhor os sujeitos que fazem parte da comunidade acadêmica e suas condiçóes de acompanhar as propostas de ERE tornou-se uma prioridade. Saber quantos docentes e discentes necessitam de apoio institucional para ter acesso à internet, construir os ambientes virtuais e suas possibilidades de aprendizagem, possibilitar a utilização de equipamentos para sua inclusão imediata, são, com certeza, desafios inesperados; no entanto, estão obrigando as universidades a conhecerem melhor suas capacidades e necessidades para cumprir melhor suas missōes.

Soluçôes tecnológicas não resolvem por completo o problema, mas, sendo pré-requisitos incontornáveis, demandam intervençóes imediatas, tanto do MEC quanto das próprias universidades, seja aproveitando as estruturas e os programas existentes como o PNAES, para aquisição e distribuição de chips de dados e de equipamentos, e a infraestrutura de acesso à internet disponível nos campi, para viabilizar as condiçôes tecnológicas mínimas para acesso às atividades remotas por parte de quem sequer dispóe de sinal de internet em casa -, seja introduzindo programas emergenciais - como parece ter sido o caso da intervençáo introduzida pelo MEC por meio da RNP. ${ }^{6}$ Outras questôes relevantes nesse debate - que vão desde letramento digital, formação continuada e adequaçôes pedagógicas e gerenciais até condiçóes domiciliares apropriadas ao estudo remoto - também demandarão atenção de gestores e decisores públicos.

6. Conforme termo de referência disponível em RNP (2020). 
Utilizar de forma mais eficiente os dados que já estão sendo construídos sobre os sujeitos que fazem parte das universidades e suas relaçóes com a sociedade torna-se uma necessidade cada vez mais premente. Ter um melhor conhecimento sobre as condiçóes socioeconômicas dos sujeitos é essencial para estabelecer parâmetros que auxiliem no planejamento da implantação do ERE.

As questóes didático-metodológicas envolvidas em tal turbilhão de mudanças também assumem um peso central na configuraçáo das respostas atuais aos desafios institucionais: além de reconhecer as vicissitudes do ERE, há que se pensar institucionalmente no passo histórico seguinte, pois as esperanças mundiais estão voltadas para a resolução do processo da pandemia, com a volta às atividades sociais e mitigação do isolamento social; com a volta das atividades presenciais para os vários níveis da educação nos países.

As questóes que conduzirão as políticas educacionais para a educação superior tendem a incorporar o aprendizado de tudo o que foi criado no enfrentamento à pandemia da Covid-19 e nos aguardam novas investigaçóes sobre como o ensino presencial não prescindirá de tudo o que foi aprendido na fase do ERE, na construção de novas metodologias e práticas voltadas para o ensino híbrido, tendo como central a figura do discente como sujeito ativo do processo de ensino-aprendizagem.

\section{REFERÊNCIAS}

ANDIFES - ASSOCIAÇÃO NACIONAL DOS DIRIGENTES DAS INSTITUIÇÓES FEDERAIS DE ENSINO SUPERIOR. Reitores fazem relatos sobre as experiências de ensino remoto em seminário da Andifes. Portal Andifes. 2020. Disponível em: https://bit. ly/2RfGfFG. Acesso em: 3 ago. 2020.

BARR. R.; TAGG, J. From teaching to learning: a new paradigm for undergraduate education. Change: the magazine of higher learning, v. 27, n. 6, p. 12-26, 1995. Disponível em: $<$ https://bit.ly/3kMkhYZ>. Acesso em: 15 jul. 2020.

BRASIL. Ministério da Educação. Coronavírus: monitoramento nas instituições de ensino. Brasília: MEC, 2020. Disponível em: <https://bit.ly/30nubqn>. Acesso em: 14 jun. 2020.

INEP - INSTITUTO DE ESTUDOS E PESQUISAS EDUCACIONAIS ANÍSIO TEIXEIRA. Sinopse estatística do Censo da Educação Superior. Edição 2009. Brasília: Inep, 2010. Disponível em: <https://bit.ly/2AhaaIR>. Acesso em: 30 jun. 2020.

Sinopse estatística do Censo da Educação Superior. Edição 2013. Brasília: Inep, 2014. Disponível em: <https://bit.ly/2AhaaIR>. Acesso em: 30 jun. 2020. 
Censo da Educaçáo Superior: notas estatísticas 2017. Brasília: Inep, 2018. Disponível em: <https://bit.ly/3hToJlT>. Acesso em: 8 jul. 2020.

Sinopse estatística do Censo da Educação Superior. Edição 2018. Brasília: Inep, 2019. Disponível em: <https://bit.ly/2AhaaIR>. Acesso em: 30 jun. 2020.

Sinopse estatística do Censo da Educação Superior. Edição 2019. Brasília: Inep, 2020. Disponível em: <https://bit.ly/2AhaaIR>. Acesso em: 30 jun. 2020.

CROSS, D.; THOMSON, S.; SINCLAIR, A. Research in Brazil: a report for Capes by Clarivate Analytics. Brasília: Capes, 2018. Disponível em: <https://bit.ly/3cdl9mQ>. Acesso em: 30 abr. 2020 .

DONOSO-DÍAZ, S.; ITURRIETA, T. N.; TRAVERSO, G. D. Sistemas de alerta temprana para estudiantes en riesgo de abandono de la educación superior. Ensaio: avaliaçáo e políticas públicas em educaçáo, Rio de Janeiro, v. 26, n. 100, p. 944-967, jul.-set. 2018. Disponível em: <https://bit.ly/3rwnUVk>. Acesso em: 14 jul. 2020.

HODGES, C. et al. The difference between emergency remote teaching and online learning. Educase Review, 27 Mar. 2020. Disponível em: <https://bitlyli.com/rH7rw>. Acesso em: 15 jul. 2020.

IBGE - INSTITUTO BRASILEIRO DE GEOGRAFIA E ESTATÍSTICA. Pesquisa Nacional por Amostra de Domicílios Contínua 2018 (PNAD Contínua 2018). Rio de Janeiro: IBGE, 2019. Disponível em: <https://bit.ly/3f3tds9>. Acesso em: 30 abr. 2020.

NASCIMENTO, P. M. et al. Acesso domiciliar à internet e ensino remoto durante a pandemia. Brasília: Ipea, 2020. (Nota Técnica, n. 88).

OMS - ORGANIZAÇÃO MUNDIAL DA SAÚDE. Timeline of WHO's response to Covid-19. 2020. Disponível em: <https://bit.ly/2OB7SLM>. Acesso em: 14 jul. 2020.

REIMERS, F.; SCHLEICHER, A. A framework to guide education response to the Covid-19 pandemic of 2020. 2020. Disponível em: <https://bit.ly/30rOW4h>. Acesso em: 14 jul. 2020.

RNP - REDE NACIONAL DE ENSINO E PESQUISA. Termo de referência: contratação emergencial de pacote de dados móveis do serviço móvel pessoal, para alunos em condição de vulnerabilidade socioeconômica de universidades públicas federais (Ifes) e de instituiçóes da rede federal de educação profissional, científica e tecnológica (RFEPCT). Brasília: RNP, jul. 2020 .

ROVAI, A. P.; JORDAN, H. Blended learning and sense of community: a comparative analysis with traditional and fully online graduate courses. The International Review of Research in Open and Distributed Learning, v. 5, n. 2, ago. 2004. Disponível em: <https://bit. ly/3v7lDSL>. Acesso em: 15 jul. 2020. 
SCHWARTZMAN, S. Acesso à internet dos estudantes de nível superior. Simon's site, 15 maio 2020. Disponível em: <https://bit.ly/3k7yvlG>. Acesso em: 8 set. 2020.

TEODORO, A.; VASCONCELOS, M. L. Ensinar e aprender no ensino superior: por uma epistemologia da curiosidade na formação universitária. Sáo Paulo: Cortez; Mackienze, 2005.

VALENTE, J. A.; ALMEIDA, M. E. B. Políticas de tecnologia na educação no Brasil: visão histórica e lições aprendidas. Arquivos Analíticos de Políticas Educativas, v. 28, n. 94, jun. 2020, p. 1-31. Disponível em: <https://bit.ly/3ccTaSV>. Acesso em: 14 jul. 2020. 

Ipea - Instituto de Pesquisa Econômica Aplicada

\section{Assessoria de Imprensa e Comunicação}

\section{EDITORIAL}

\section{Chefe do Editorial}

Reginaldo da Silva Domingos

\section{Assistentes da Chefia}

Rafael Augusto Ferreira Cardoso

Samuel Elias de Souza

\section{Supervisão}

Camilla de Miranda Mariath Gomes

Everson da Silva Moura

\section{Editoração}

Aeromilson Trajano de Mesquita

Cristiano Ferreira de Araújo

Danilo Leite de Macedo Tavares

Herllyson da Silva Souza

Jeovah Herculano Szervinsk Junior

Leonardo Hideki Higa

\section{Capa}

Danielle de Oliveira Ayres

Flaviane Dias de Sant'ana

\section{Projeto Gráfico}

Renato Rodrigues Bueno

The manuscripts in languages other than Portuguese published herein have not been proofread.

\section{Livraria Ipea}

SBS - Quadra 1 - Bloco J - Ed. BNDES, Térreo

70076-900 - Brasília - DF

Tel.: (61) 2026-5336

Correio eletrônico: livraria@ipea.gov.br 

Composto em adobe garamond pro 12/16 (texto) Frutiger 67 bold condensed (títulos, gráficos e tabelas) Brasília-DF 



\section{Missão do Ipea}

Aprimorar as políticas públicas essenciais ao desenvolvimento brasileiro por meio da produção e disseminação de conhecimentos e da assessoria ao Estado nas suas decisões estratégicas.

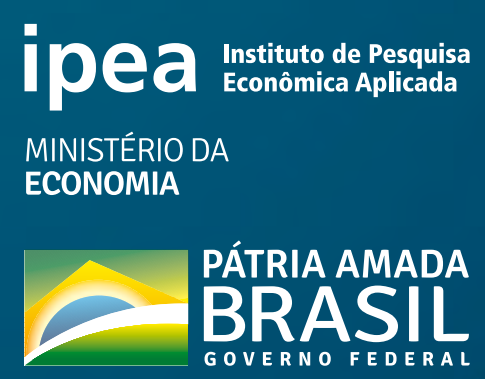

